\title{
Making and breaking bones: learning physics through engineering design
}

\author{
Alexandria K. Hansen, and Danielle B. Harlow \\ Gevirtz Graduate School of Education, University of California, Santa Barbara, 93106-9490
}

\begin{abstract}
Eighth grade students in an engineering course designed and tested prosthetic bones for use in a movie. Bone design required physics content to be integrated with knowledge of math, engineering, and technology. Specifically, students used a 3D printer and associated design software to design, fabricate, and test a prosthetic fibula for a stuntman's use in a movie. This paper explains how the project motivated students' use of physics content and further required students to use their knowledge of physics (e.g., force, motion, and pressure) in coordination with other content knowledge.
\end{abstract}

\section{INTRODUCTION}

Digital fabrication and design (e.g., 3D printing) is emerging as an engaging approach to combine the disciplines of Science, Technology, Engineering, and Mathematics (STEM) in K-12 education. Research in this area has focused on increasing participation in STEM [1], identity [2], and access for underrepresented populations $[3,4]$. We focus on how these types of activities provide alternative opportunities for students to learn physics content. Specifically, we look at how a design challenge to design, print, and test a prosthetic bone for use as a movie prop provided opportunities for students to learn about density, forces, and materials.

Two movements in education are relevant to our work: The Next Generation Science Standards (NGSS) and the Maker Movement. The NGSS [5] describe a vision of K-12 science education that differ from previous standards in that teachers must actively engage students in learning science content through the practices of professional scientists and engineers: practices such as asking questions, developing models, and constructing scientific explanations and engineering solutions. Additionally, the NGSS explicitly includes engineering design as content to learn about and is integrated into performance expectations for physics and the other sciences. Including engineering was done in an effort to improve how students from underrepresented populations identify with science and to offer opportunities for innovation and creativity at the K-12 level [5]. While the intention is that students will interact with and learn science content knowledge while solving these engineering problems, research in this area is limited.

Coupled with this change in schools, the "Maker Movement" has influenced both informal (e.g., museums, libraries) and formal education (school) settings, and has been endorsed by the White House as a legitimate means of increasing STEM participation [6]. This movement "represents a growing movement of hobbyists, tinkerers, engineers, hackers, and artists committed to creatively designing and building material objects for both playful and useful ends" [7]. By providing opportunities for active construction in STEM-rich contexts, students have the power to transcend their role as technological consumers, and become producers of technological artifacts and of their own knowledge, skills, and learning experiences [4].

While making is not synonymous with engineering, the ideas are related. Engineering includes specific design goals and constraints as well as mathematical tests to optimize among competing designs. Learning science content through engineering may potentially create opportunities in which students want to learn more disciplinary content in order to complete a design. Moreover, productive design challenges may provide opportunities for students to both learn science content explicitly and "bump up against" additional STEM content [8]. For example, in order for a student to complete a design that involves using LEDs, they must learn about electricity and circuits but they may also learn about other content, depending on the design challenge and design. The design challenge precedes the need to know certain content, and provides a motivating context in which to learn the necessary content to complete the design.

This paper reports on a qualitative, case study of an $8^{\text {th }}$ grade Creative Design \& Engineering Course in which the teacher used digital fabrication to combine the disciplines of STEM in an engaging manner, and provided opportunities for students to "bump up against" physics content [8] without explicit instruction. The paper is organized as follows. An overview of the research context and methods are described, followed by findings that highlight the opportunities for learning physics content when participating students engaged in a digital fabrication project.

\section{STUDY DESIGN AND CONTEXT}

This study took place in an $8^{\text {th }}$ grade Creative Design and Engineering course at a small private school. It was a required course for all students and was taught by the school science teacher (Ms. Taylor) and an aide (Ms. Wilson). 14 of 15 enrolled students agreed to participate in this study: 7 male and 7 female. All student and teacher names used in this report are pseudonyms. 
In the year prior to this study, Ms. Taylor offered a similar course, but a greater number of male students elected to enroll than female students. Because the school and teacher felt that this was an essential learning experience for all students, the course was made mandatory in the following academic year, resulting in more equal gender distribution.

In the course, the teacher provided experiences for students to design both digitally and physically. For example, students programmed interactive stories and games using Scratch (http://scratch.mit.edu), built robots, experimented with a Makey Makey device (http://makeymakey.com), and gained experience using a 3D printer. Additionally, the teacher wanted students designing in authentic contexts and for authentic audiences. They designed products for children at a local hospital, ornaments for the White House holiday tree, and other audiences.

In earlier work [9], we described students' perceptions of the engineering and science classes (taken simultaneously and with the same teacher). The students perceived the instruction in the engineering class as allowing for experimentation and learning though failure. In contrast, they saw the science class as focused on confirmatory experiments and a focus on doing things correctly.

\section{A. The design challenge}

The teacher collaborated with a professional stuntman (also an enrolled student's father) who was missing part of his leg. This was an important characteristic for the project task because stunt doubles with amputations can use prosthetic body parts that break, explode, or otherwise are destroyed for cinematic effect without harming the actor. Students were tasked with fabricating a prosthetic bone that the stuntman would use as a prop in a movie he was currently working on. The finished bone was required to look realistic and break with realistic fracturing when a force was exerted. The final bone design was also required to fit into a "holder/connector," measuring 200 millimeters in length and 30 millimeters in diameter. After the bones were designed, printed on a 3D printer, and tested, the bone that best fit the design constraints would be used as an actual prop in the movie. The stuntman and make-up artists would add artificial skin and blood to the bone for use in the movie scene. Students worked in groups of 2-4 to complete this digital fabrication project over the course of 6 months. Fig. 1 shows the bones being placed into the prosthetic lower leg.

\section{B. Research design and methods}

This research is part of a qualitative, descriptive, case study [10]. A case study design is particularly well suited for studying a phenomenon that is impossible to separate from the context itself [11]. In this research, the bounded case under investigation is the Creative Design and

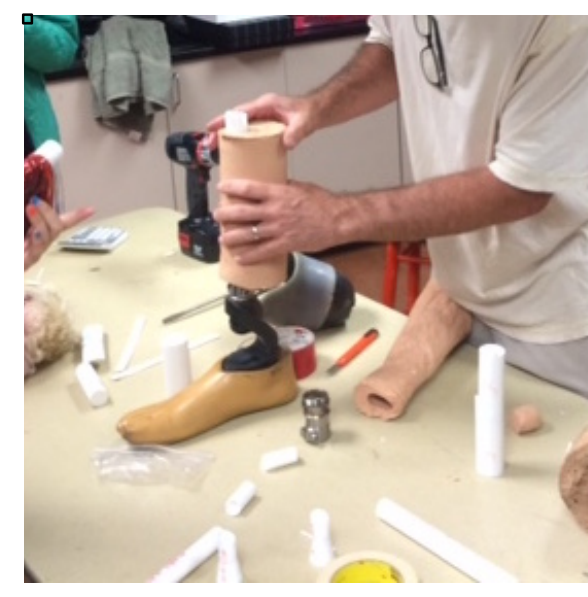

FIG 1. Student designed bones (white objects) being placed into the prosthetic leg for testing.

Engineering classroom throughout the prosthetic bone fabrication project. The primary research question addressed in this study is: What opportunities for learning physics content were created within the context of this engineering design project?

Data collection included classroom observations from an ethnographic perspective [12]. Ethnography "is the art and science of describing a group or culture" [13]. Ethnographic field notes were collected on 20 hours of class meetings, documenting students' design process weekly over the course of this six-month long digital fabrication project.

We also conducted semi-structured interviews with the teacher at the completion of the project and 4 focus groups (13 students). The teacher interview included questions about her motivation, planning, and instruction. The student focus groups included questions regarding the 3D design experience and their use of disciplinary content knowledge.

We considered the class and the digital fabrication project to be an activity system and used cultural historical activity theory [14] to inform the coding of transcribed interviews and observations. Here, we focus only on a subset of the codes-those that identify instances where students recognized their use of scientific concepts throughout their design process. In the full coding scheme, physics content knowledge was just one of the many conceptual and physical tools that students used to design their bones.

\section{FINDINGS}

We discuss two findings related to the students' learning of physics content. The first is that this experience motivated students to learn physics. The second is that the design task provided opportunities for students to integrate physics content with other disciplinary content areas. A more through analysis of the classroom and project under investigation can be found here, [15]. 


\section{A. Design task motivated use of physics content}

From the students' perspective, the final product (the prosthetic bone), not the science content, was the explicit focus of the unit. This was in contrast to their science class (taken simultaneously and with the same teacher) where units were centered on disciplinary content and organized around chapters of a textbook. One student described how the activity required her group to use physics content knowledge.

Sadie: We definitely did use different ideas revolving around science. And, like, if we hit [the bone] one way, which way would it go. Kind of like, force and momentum. Like, if I swing it like this, will it still continue, or will it just stop. Or, at what point [is] the breaking factor? Like, how thin will the [bone] need to be in order to do this? Or, is this too much structure, or not enough? So, there were definitely some underlying ideas of science, but not like get out a book and flip through it, and [ask] what ideas does this revolve around?

Sadie described how her group used physics content knowledge in order to design their bone and highlighted that there was no requirement to "get out a book and flip through it." Rather, Sadie described an active process of design and construction, where her group iterated on their design using physics concepts such as force and momentum.

Classroom observations confirmed that students used knowledge of physics to inform their designs. For example, during one class meeting, a group of students discussed their ideas with their classroom teaching assistant (also an expert in 3D printing design and materials).

Sydney: We discovered that the breaking point [of the bone] needs to be off-center.

Taylor: Can we make hollow sections within the bone to help it splinter, like bubbles?

This led to a conversation about density and a discussion about making the holes inside the bone bigger to make the object as a whole less dense. One student then suggested an alternative design, asking:

Sydney: Could we design it [a separation in the bone] at a certain angle, where half the bone just slides out and forces the other half to move?

Ms. Wilson compared this to a hubcap, which can either be screwed or pushed onto the car's wheel.

Sydney: We could design smaller pieces coming off the bone that would allow it to connect to the other piece, kind of like Legos.

Ms. Wilson: Yeah, those connecting pieces are called keys.

Taylor: Okay, well keys.

S2: I think the sliding design might work.

This was followed by a discussion about force, and where the initial force would come from, and how that force would impact the other parts of the bone.

In the conversation above, the physics topics emerged from the group's design ideas. When one student suggested adding, "hollow sections...like bubbles" within the bone, a conversation followed about density and how the "bubbles" might change the density of the design. Similarly, when the students moved onto another design idea that involved printing the bone in two separate pieces, but connected through the use of extruding "keys," the conversation focused on forces. Through brainstorming with the class assistant, the students were able to refine their ideas over time, using physics content knowledge, not because they were assigned to do so, but because it helped them improve their design. See Figure 2 for an image of this interaction.

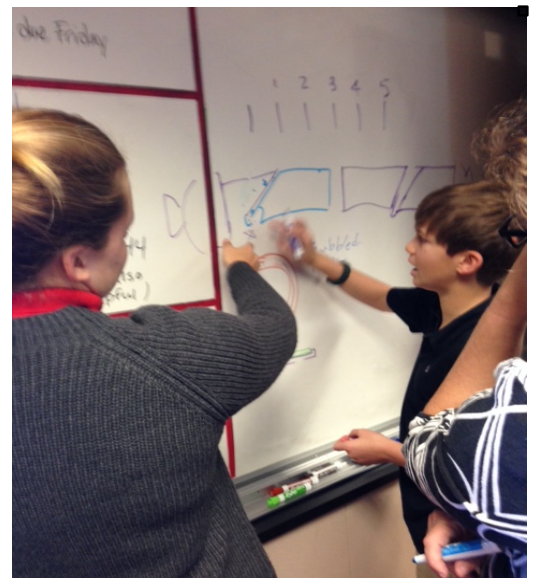

FIG. 2 Ms. Wilson and the students discussing the ideas of density and force to complete the bone design.

\section{B. Physics content was integrated with other areas}

At the core of this project was students' developing understanding of forces and stresses. But, by engaging in engineering design, physics content was not isolated from other content areas.

Students used engineering design by iteratively creating prototypes to ensure their product was meeting predetermined constraints. For example, one of the constraints of the project was that the bone splintered when it broke. This was to produce the desired effect for the movie. One group observed another group test their bone and saw that it broke evenly instead of splintering. This led them to iterate on their design and place a hollow jagged structure inside the bone, allowing the bone to break evenly, yet appear jagged.

Mathematics was also embedded in the design process. Students converted between inches and millimeters, as well as used their knowledge of angles and proportions to create their designs. For example the group discussed earlier (shown in Fig. 2) refined their initial design using knowledge of triangles, while another group of students used algebra to calculate the different lengths of each protruding "key" so that the two pieces could connect seamlessly (design shown in Fig. 3).

Students also integrated physics knowledge with other science knowledge to create a bone that looked realistic and would fracture in a realistic manner when an outside force was applied. To do so, students drew from their understanding of anatomy. One pair of students noted this in the focus group when asked if they used science content 
knowledge while designing. They described comparing their designed bones to real bones. Additionally, students depended upon their understanding of force, pressure, and density to create a realistic final product, as previously discussed.

Finally, technology was an integral part of this project. Students created their designs using TinkerCAD (https://www.tinkercad.com)_free, publically accessible design software that functions within an Internet browser and on iPads (see Figure 3) - and then printed their designs using a $3 \mathrm{D}$ printer.

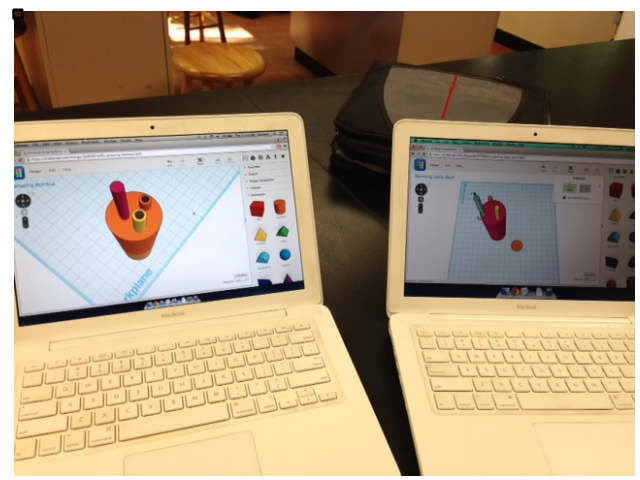

FIG 3. TinkerCAD design software, showing early prototype bone designs by one group of students.

\section{DISCUSSION}

With the adoption of the Next Generation Science Standards, K-12 schools will begin to integrate engineering design in their courses, both as a new content area and as a way to build students understanding of physics, biology, chemistry and earth science content. It is possible for this change to broaden participation in physics and other STEM areas by helping students to see physics as an essential component to solving practical problems.

[1] P. Blikstein, V. Chen, A. Martin, in ICLS Proceedings. Boulder, 2014.

[2] L. Martin, C. Dixon, in IDC Proceedings. New York, 2013.

[3] B. Buchholz, K. Shively, K. Peppler, K. Wohlwend, Mind, Culture, and Activity, 21, 4, 2014.

[4] P. Blikstein, In J. Walter-Herrmann \& C. Büching (Eds.), FabLabs: Of Machines, Makers and Inventors. (Transcript Publishers, Bielefeld, 2013)

[5] NGSS Lead States. Next Generation Science Standards: For States, By States (2013).

[6]http://www.whitehouse.gov/blog/2014/02/03/announcing -first-white-housemaker-faire.

[7] L. Martin, J of Pre-College Engineering Education Research, 5(1), 2015.

[8] D. Bennet, D., \& P. Monahan, P. NYSCI design lab:

In M. Honey \& D. Kanter (Eds.), Design Make Play: Growing the Next Generation of STEM Innovators (Routledge, New York, 2013).
This change in K-12 schooling may also impact students' understanding of physics and the types of physics ideas they hold when entering post-secondary education. It is critical that we investigate how students are interacting with physics in engineering design tasks and the type of content knowledge they are developing.

This study was a first step. Our goal was to describe whether and how a group of middle school students identified the physics in the project they were working on. We observed that in the design task, students were focused on their artifact (a prosthetic bone) and its intended use (a movie prop). The focus on making their bone behave in ways consistent with the design goals motivated them to consider forces, density, pressure and the physics of materials. Moreover, they considered these topics along with mathematics and anatomy, and in the context of participating in an iterative engineering design cycle using technology.

We were limited in that we studied one group of students involved in one engineering project and with a teacher who simultaneously worked with the same set of students in a more traditional science class. This is an ideal circumstance and, as such, our findings are not generalizable. Instead they describe what is possible in a best case scenario. To effectively design engineering tasks that are both engaging to students and help students develop physics content knowledge and to prepare teachers to facilitate such activities will require careful consideration and additional research.

\section{ACKNOWLEDGEMENTS}

The authors wish to thank the students and teachers who generously allowed us into their classroom to complete this research.

[9] A. Hansen, J. McBeath, D. Harlow. (2016, April). AERA, Washington, DC, 2016.

[10] S. Merriam, S.B. Qualitative research and case study application in education. (Jossey-Bass, San Francisco, 1998).

[11] R. Yin, R. Evaluation Practice, 15,3, 1994.

[12] J. Green, A. Skukauskaite, D. Baker, D. In J. Arthur, M. Waring, R. Coe \& L.V. Hedges (Eds.), Research Methods and Methodologies in Education (309-321). (Sage, Thousand Oaks, 2012).

[13] G. Walford, How to do educational ethnography (Tufnell Press, London, 2012).

[14] Y. Engeström, Learning by expanding: An activitytheoretical approach to developmental research. (Orienta-Konsultit, Helsinki,1987).

[15] A.K. Hansen (unpublished thesis). Making meaning of making: Using CHAT to understand digital fabrication in the classroom. Retrieved from http://www.alexandriahansen.com/uploads/4/0/3/6/403 65295/akhansen_ma_thesis.pdf. 